\title{
O Problema Mente-Cérebro em Freud
}

\author{
Gilberto Gomes ${ }^{1}$ \\ Universidade Estadual do Norte Fluminense
}

\begin{abstract}
RESUMO - Em suas obras posteriores, Freud abandona a pretensão do Projeto de uma psicologia (1895) de formular hipóteses específicas sobre o fundamento neural do psíquico, mas continua a conceber esse fundamento como real. Não adotou uma posição dualista sobre o problema mente-cérebro, como pode ser comprovado por inúmeras citações. Isso não o leva, entretanto, a buscar substituir conceitos psicológicos por conceitos fisiológicos, mas permite atribuir ao psíquico uma causalidade natural, uma dimensão quantitativa e uma estrutura espacial (tópica). A concepção freudiana da relação mentecérebro pode ser considerada como uma teoria do duplo aspecto ou da identidade psiconeural.
\end{abstract}

Palavras-chave: psicanálise; problema mente-cérebro; dualismo; monismo; Freud.

\section{The Mind-Brain Problem in Freud}

\begin{abstract}
In his later works, Freud abandons the aim of the Project of a scientific psychology (1895) of formulating specific hypotheses about the neural basis of psychical phenomena, but continues to conceive this basis as real. He did not adopt a dualist position concerning the mind-brain problem, as can be confirmed by innumerous quotations. This does not lead him, however, to try to substitute physiological concepts for psychological ones, but enables him to attribute to psychical processes natural causality, a quantitative dimension and a spatial (topographic) structure. The Freudian conception of the mind-brain relation may be considered as a double-aspect theory or a psychoneural identity theory.
\end{abstract}

Key words: psychoanalysis; mind-brain problem; dualism; monism; Freud.

A teoria freudiana é muitas vezes apresentada como se representasse uma ruptura em relação à concepção de que os fenômenos psíquicos derivam da atividade de sistemas neurais. Ela seria uma teoria "mentalista", em oposição a uma teoria "organicista". A publicação da correspondência com Fliess e, sobretudo, do Projeto de uma psicologia, ocorreu só em 1950, quando já estavam definidas as principais linhas de interpretação da obra freudiana. Tais trabalhos se apresentaram como um desafio à atribuição a Freud de uma posição dualista. Houve tentativas de desqualificar o Projeto como obra pré-psicanalítica, cujo principal interesse seria o de ter sido rejeitado por seu próprio autor (por exemplo, Erikson, 1955). Serviria para mostrar aquilo de que o autor teria tido que se desembaraçar para criar a teoria psicanalítica. Forçoso era admitir, no entanto, que o Projeto comportava notáveis antecipações de formulações teóricas futuras. Sua importância teórica foi cada vez mais reconhecida, mas foi muitas vezes visto como testemunho de um resto de concepções reducionistas das quais o autor teria ainda que de desvencilhar. Não há dúvida de que Freud rejeitou o Projeto. Nem há dúvida de que ele abandonou qualquer pretensão de dar explicações neurofisiológicas para os processos psíquicos. Isso não significa, entretanto, que tenha adotado uma posição dualista em relação ao problema mente-cérebro (Kanzer, 1973). No presente trabalho, pretendemos mostrar qual a posição adotada por Freud em relação a esse problema, em diferentes etapas de sua obra. Discutirei, ainda, algumas conseqüências dessa posição para a elaboração de sua teoria.

1 Endereço: Rua Lopes Quintas, 100, 605-I, Rio de Janeiro, RJ, Brasil 22460-010.E-mail: ggomes@uenf.br

\section{O problema mente-cérebro em Freud, antes de 1900}

Freud começou seus trabalhos sobre os fenômenos psíquicos admitindo a concepção de que estes são produzidos por - ou se identificam a - processos neurais. Isso fica bem claro no Projeto de uma psicologia, onde anuncia que seu objetivo é formular "uma psicologia ciência natural, isto é, apresentar os processos psíquicos como estados quantitativamente definidos de partes materiais especificáveis (...) [que são] os neurônios" (Freud, 1950/1987, p. 387)² Mesmo antes de 1895 , ele já havia expressado esse ponto de vista. Em 1888, no prefácio da tradução do livro de Bernheim, De la suggestion, escreve:

Pode-se colocar a questão de saber se todos os fenômenos da hipnose devem passar em algum lugar através da esfera psíquica; em outras palavras - pois a questão não pode ter outro sentido - se as mudanças de excitabilidade que ocorrem na hipnose afetam invariavelmente apenas a região do córtex cerebral. (Freud, 1888/1966, p. 84)

Em 1891, em seu livro sobre as afasias, escreve: "O processo psíquico é, assim, paralelo ao processo fisiológico ( 'a dependent concomitant')" (Freud, 1891/1957a, p. 207)3

\section{O problema mente-cérebro em Freud, após 1900}

É habitual admitir que Freud mudou, mais tarde, sua concepção sobre a natureza do psíquico (Strachey, 1957).

2 As citações de Freud foram traduzidas a partir das fontes citadas.

3 A expressão a dependent concomitant está em inglês no original, e é atribuída pelo tradutor J. Strachey a Hughlings Jackson. 
Na verdade, é fácil mostrar que isso não ocorreu. Em sua obra A interpretação dos sonhos, afirma: "Se fosse apenas possível confirmar que a memória e a qualidade para a consciência se excluem mutuamente nos sistemas $\psi$, uma perspectiva muito promissora se abriria sobre as condições da excitação dos neurônios" (Freud, 1900/1982a, p. 516). Vemos a identificação do que se passa nos sistemas $\psi(\mathrm{e}$, especificamente, da memória e da consciência) com o funcionamento neuronal. Mais adiante, ao falar da diferença entre processo primário e processo secundário, afirma: " $A$ mecânica desses processos me é completamente desconhecida; aquele que quisesse tomar essas idéias a sério deveria procurar as analogias físicas e abrir para si mesmo um caminho para a figuração do processo de movimento da excitação neuronal" (Freud, 1900/1982a, p. 569). Fica claro que os processos psíquicos primário e secundário são vistos como dependendo da excitação neuronal. Ele abandonou a pretensão, que tinha à época do Projeto, de formular hipóteses específicas sobre a base neurofisiológica dos processos psíquicos, possivelmente por não ter como fundamentá-los ou confirmá-los, mas continua a conceber esse fundamento neurofisiológico como real.

Em 1905, escreve: "devo acrescentar que não faço qualquer tentativa para proclamar que as células e fibras nervosas, ou os sistemas de neurônios que as substituem hoje, sejam essas vias psíquicas (...)"(Freud, 1905/1960, p. 148). Seria possível citar essa frase como prova do abandono da concepção que o psíquico resulta da atividade neural. Mas é preciso ler a continuação da passagem: “(...) se bem que deveria ser possível, de uma forma que ainda não pode ser indicada, representar essas vias por elementos orgânicos do sistema nervoso" (Freud, 1905/1960, p. 148).

Ainda não é possível ter essa representação neural dos processos psíquicos, mas, segundo o autor, isso "deveria ser possível”. Nos Três ensaios sobre a teoria sexual, lemos:

\section{É, portanto, provável que substâncias químicas especiais sejam produzidas na porção intersticial das glândulas sexuais; essas são então levadas pela corrente sanguínea e fazem com que partes particulares do sistema nervoso central sejam carre- gadas de tensão sexual. (...) A questão de como a excitação sexual emerge da estimulação das zonas erógenas, quando o aparelho central foi previamente carregado, (...) [não pode ser respondida], mesmo a título de hipótese, no estado presente de nosso conhecimento." (Freud, 1905/1953a, p. 215)}

Vemos que a concepção de base é psicofisiológica, mesmo se ele considera impossível, no momento, formular hipóteses específicas sobre esse fundamento fisiológico do psíquico.

Na obra de 1914, Para a introdução do narcisismo, encontramos:

deve-se lembrar que todas as nossas concepções psicológicas provisórias deverão um dia se apoiar sobre o solo de suportes orgânicos. Torna-se então provável que sejam substâncias e processos químicos particulares que realizem as operações $d a$ sexualidade (...). Levamos em conta essa verossimilhança ao substituirmos as substâncias químicas particulares por forças psíquicas particulares. (Freud, 1914/1946, p. 144)
Em Pulsões e destinos das pulsões, o autor atribui ao sistema nervoso, mais uma vez, as funções psíquicas:

Os estímulos pulsionais (...) têm, portanto, exigências muito mais fortes em relação ao sistema nervoso, que o levam a atividades complexas e interconectadas, modificando o mundo exterior a tal ponto que este venha a oferecer a satisfação às fontes da pulsão (...) são as pulsões (...) que levaram o sistema nervoso (...) à sua presente altura de desenvolvimento. (Freud, $1915 / 1982$ b, p. 84)

Quando uma representação é transposta do sistema inconsciente ao sistema pré-consciente, forma-se um segundo registro da representação? Freud coloca a questão em $O$ inconsciente, e diz que ela "é difícil pois ultrapassa o psicológico puro e toca nas relações do aparelho psíquico com a anatomia" (Freud, 1915/1982c, p. 133).

Embora repudie, em seguida, as tentativas de localização das funções psíquicas, conclui dizendo o seguinte: "Nossa tópica psíquica não tem, provisoriamente, nada a ver com a anatomia; ela se refere a regiões do aparelho psíquico, onde quer que possam estar situadas no corpo" (Freud, $1915 / 1982$ c, p. 133). Isto quer dizer que, a seu ver, elas estão situadas no corpo - e é o próprio autor que sublinha a palavra "provisoriamente", ao dizer que sua tópica nada ter a ver com a anatomia.

Em Luto e melancolia, após observar que a freqüente melhora vespertina indica um provável fator somático, o autor se pergunta se certas formas da doença não poderiam ser produzidas por um empobrecimento da libido do eu causado diretamente por toxinas (Freud, 1917/1957b, p. 253). Produtos corporais (toxinas) são considerados como diretamente responsáveis por um estado do aparelho psíquico (a diminuição da libido do eu).

É conhecida a oposição feita pelo autor entre a energia psíquica "ligada" e a "livre", mas, em Além do princípio do prazer, em lugar de "energia psíquica ligada", Freud (1920/1955a, p. 234) escreve "processo nervoso ligado", o que mostra que, para ele, a energia psíquica depende de um processo nervoso. Na mesma obra, lemos: "A tendência dominante da vida psíquica, talvez da vida nervosa em geral (...)" (Freud, 1920/1955a, p. 255)

Vemos assim a vida psíquica colocada como um caso particular da vida nervosa.

Do ano de 1930, temos a seguinte afirmação: "A hipótese da conservação de tudo o que é passado só vale, também para a vida anímica, sob a condição de que o órgão da psique tenha se conservado intacto, que seu tecido não tenha sofrido nem trauma nem inflamação" (Freud, 1930/1994, pp. 256-257).

O órgão cujo tecido pode sofrer trauma ou inflamação é, evidentemente, o cérebro. Em seus últimos trabalhos, encontramos expressões das mais explícitas sobre a questão." $D o$ que chamamos nossa psique (ou vida psíquica), duas coisas nos são conhecidas; primeiramente, seu órgão corporal e cena de ação, o cérebro (sistema nervoso) (...)" (Freud, 1938/1941, p. 67).

Para muitos, (...) basta supor que somente a consciência seja o psíquico (...) Entretanto, os processos conscientes não for- 
mam, segundo acordo geral, séries ininterruptas e completas em si mesmas, de maneira que nada mais resta a fazer do que supor processos físicos ou somáticos concomitantes ao psíquico, aos quais deve-se atribuir uma completude maior que às séries psíquicas, pois alguns deles têm processos paralelos conscientes, mas outros não. Isso sugere, então, naturalmente, que acentuemos, na psicologia, esses processos somáticos, que reconheçamos neles o verdadeiro psíquico ["das eigentlich Psychische”] (...) (Freud, 1938/1941, pp. 79-80)

Mais à frente, ele escreve: "energia nervosa ou psíquica" (Freud, 1938/1941, p. 86), e, ainda no mesmo texto, antecipando-se à descoberta dos antipsicóticos e antidepressivos, propõe: "O futuro poderá nos ensinar a exercer uma influência direta, por meio de substâncias químicas particulares, sobre as quantidades de energia e sua distribuição no aparelho psíquico" (Freud, 1938/1941, p. 108). Torna-se claro que, ao longo de toda sua obra, Freud considerou a atividade psíquica como tendo fundamento nos processos neurofisiológicos do cérebro.

\section{Implicações de uma visão monista da relação mente- cérebro}

Quais as conseqüências desta concepção do psíquico como fundamentado num substrato neurofisiológico? Para alguns, uma tal concepção significa que deveríamos substituir os conceitos e explicações de natureza psicológica por conceitos e explicações neurofisiológicos. Conceitos como representação, desejo, pensamento, intenção e atenção, entre outros, deveriam ser substituídos por conceitos como excitação, inibição ou reflexo. Nessa perspectiva, tudo que nos é oferecido pelo "sentido interno", ou nossa consciência de nós mesmos, deveria ser considerado como não pertinente ou enganoso. $\mathrm{O}$ método de pesquisa deveria ignorar a introspecção e privilegiar os procedimentos do laboratório de fisiologia ou os procedimentos experimentais baseados na observação objetiva do comportamento. Todo fenômeno deveria ser explicado em função de fatores antecedentes e objetivos. Sobretudo, toda explicação teleológica deveria ser evitada, isto é, toda explicação de um fato em função de sua "finalidade" ou "alvo" supostos. Tal já é, em linhas gerais, e sujeita a variações de autor a autor, a abordagem de Laycock, Carpenter, Griesinger, Maudsley, Setchênov, Luys e Ribot, no século XIX (Gauchet, 1992), e, no início do século XX, de forma muito rigorosa, a de Pavlov (1961).

Evidentemente, a abordagem de Freud é totalmente outra. Mesmo na época em que acreditava que devia - e podia - formular hipóteses específicas sobre a base fisiológica do psíquico - isto é, na época do Projeto de uma psicologia - pode-se constatar que não é tanto sua psicologia que se torna fisiológica, mas antes sua fisiologia que se torna psicológica. Os conceitos de natureza psicológica como desejo, pensamento, prazer, etc., não são substituídos por conceitos neurofisiológicos, mas são preservados e é sua representação neurofisiológica que se dobra às exigências da teoria dos processos psíquicos. Vemos Freud inventar, ao longo de todo seu texto, a neurofisiologia que lhe convém (confrontar com a discussão de Gabbi Jr., 2003). Mais tarde, a concepção da base neural do psíquico não lhe imporá mais a tarefa de tentar uma formulação hipotética dos processos neurofisiológicos em questão e ele se contentará, então, a recorrer a instâncias e processos psíquicos para sua teoria. Essa concepção, apesar disso, permanecerá presente, como vimos, e não será sem conseqüências.

Para Freud, então, que consequiências terá a concepção da base cerebral do psíquico? Por que não podemos considerar essas afirmações sobre o substrato fisiológico como anódinas, como uma homenagem póstuma a uma concepção já ultrapassada? Essas conseqüências serão efetivamente reveladas por uma análise da metapsicologia freudiana, não como teoria puramente especulativa, como alguns a querem ver (Meltzer, 1967), mas enquanto elemento indispensável da práxis teórica de Freud. Examinaremos aqui algumas conseqüências gerais para a teoria psicanalítica.

\section{O determinismo psíquico em Freud}

Inicialmente, temos a firme adesão de Freud ao pensamento causalista. A mesma causalidade dos fenômenos estudados pelas ciências naturais se aplica, segundo ele, aos fenômenos psíquicos. Aliás, em Algumas lições elementares de psicanálise, após ter definido a psicanálise como "uma parte (...) da psicologia”, escreve: "A psicologia é também uma ciência natural. Que mais pode ela ser?" (Freud, 1938/1964, p. 282). Um Binswanger (1970) poderá criticar o naturalismo de Freud com uma imponente argumentação filosófica, mas o que nos concerne aqui é que esse naturalismo parece ter sido um ingrediente essencial de sua teoria.

A causalidade dos fenômenos psíquicos é coerente com a idéia de que estes têm um substrato natural, neural, mesmo se não se pode explicá-los em termos neurais. Para Freud, tratase sempre de explicar os fenômenos psíquicos em termos de causas e não somente de compreendê-los. A elucidação do sentido, seja dos sonhos ou dos sintomas, tem, sem dúvida, um lugar central no seu sistema, mas essa elucidação de sentido não deve se fazer como uma simples hermenêutica (Ricoeur, 1965), isto é, como uma exploração das possibilidades de significação ou de simbolização. Ao contrário, ela recorre a explicações causais relativas aos processos psíquicos inconscientes, em termos de conflitos entre instâncias com diferentes modos de funcionamento. A propósito disso, pode-se lembrar a preferência de Freud pela interpretação dos sonhos em função das idéias incidentes (Einfälle) do sonhador, em relação à interpretação simbólica: "Gostaria de fazer uma advertência expressa contra a superestimação da importância dos símbolos na interpretação dos sonhos (...) e contra o abandono da técnica que utiliza as associações do sonhador" (Freud, 1900/1953b, p. 360)

À técnica das associações, ele atribui "o primeiro lugar tanto na prática quanto na teoria" (Freud, 1900/1953b, p. 360). É evidente que a interpretação freudiana das associações deriva diretamente de um pensamento causalista: as associações que o paciente produz durante a análise e os elementos do sonho são considerados como derivados das mesmas causas. A interpretação simbólica é aceita, mas também ela só obtém para ele seu valor em relação a uma explicação causal relativa a um desejo inconsciente suposto, que se choca com um mecanismo de defesa. 
A crença do autor na causalidade psíquica é muitas vezes afirmada com um termo forte, o de determinismo psíquico. Por exemplo, na Psicopatologia da vida cotidiana, cita uma carta escrita por ele mesmo, onde diz: "nada na mente é arbitrário ou indeterminado" (Freud, 1901/1960, p. 242). E em 1910:

- “(...) apeguei-me a um preconceito (...) estava altamente persuadido do rigor do determinismo dos processos anímicos (...)" (Freud, 1910/1993, p. 26).

- “(...) o psicanalista se distingue por uma crença particularmente rigorosa no determinismo da vida anímica" (Freud, 1910/1993, p. 36).

- “(...) dois obstáculos ao reconhecimento dos caminhos de pensamento psicanalíticos: primeiramente, não ter $o$ hábito de contar com o determinismo, rigoroso e válido sem exceção, da vida anímica (...)" (Freud, 1910/1993, p. 52).

Não era ainda chegada a hora para a afirmação científica de um princípio de indeterminação como o de Heisenberg, ou para a formulação de processos estocásticos ou de autoorganização (Atlan, 1979/1992; Glansdorff \& Prigogine, 1971). A ciência da época do autor era antes estritamente determinista. Em Freud, o único meio de relativizar esse determinismo estrito foi a noção de sobredeterminação. Cada fenômeno psíquico é determinado, mas pode sê-lo ao mesmo tempo por vários fatores (Laplanche \& Pontalis, 1967/1970, pp. 641-643). A possibilidade de sempre encontrar outros determinantes e de imaginar ainda outros que não podemos precisar impõe, na realidade, uma limitação, pelo menos prática, ao determinismo psíquico freudiano. Sua posição causalista permanece, no entanto, inalterada, em coerência com sua concepção naturalista dos processos subjacentes aos fenômenos psíquicos. O determinismo psíquico adotado por Freud poderia ser visto como entrando em choque com seus conceitos de escolha de objeto e escolha da neurose. A propósito, escrevem Laplanche e Pontalis (1967/1970):

não é indiferente que, numa concepção que invoca um determinismo absoluto, apareça este termo que sugere que um acto do indivíduo é necessário para que os diferentes factores históricos e constitucionais evidenciados pela psicanálise assumam o seu sentido e o seu valor motivante. (p. 213)

A nosso ver, esse conflito é aparente, pois no sistema freudiano os próprios atos de escolha do indivíduo estão sujeitos ao determinismo psíquico.

\section{O caráter quantitativo da teoria freudiana}

Uma segunda conseqüência geral é o caráter quantitativo da teoria freudiana. Ao contrário de um Bergson (1961), por exemplo, que consagra todo um capítulo de seu Ensaio sobre os dados imediatos da consciência à contestação de que os fenômenos psíquicos possam estar sujeitos a variações quantitativas ou de intensidade, e que busca substituir as expressões quantitativas desses fenômenos por análises qualitativas, a abordagem de Freud é decididamente quantitativa. Não podemos, certamente, medir as quantidades em questão, mas a teoria nem por isso deixa de recorrer a noções fundamentais de natureza quantitativa. Tomemos, por exem- plo, o conceito de investimento (Besetzung). Ele refere-se a uma quantidade de excitação ou de energia psíquica ligada a uma representação. No processo primário, Freud supõe um deslocamento mais fácil e maior dessa quantidade, que corresponderia à busca de uma satisfação imediata. No processo secundário, por outro lado, só uma fração menor da energia de investimento se deslocaria. Além do adiamento da descarga, isso possibilitaria ainda evitar uma liberação excessiva de angústia que seria prejudicial ao processo de pensamento (Freud, 1915/1982c).

Freud busca também conceber o prazer como um processo de natureza quantitativa. Sua primeira hipótese o associa a uma descarga, ou seja, a uma redução de tensão, a uma redução do nível de investimento no aparelho psíquico. Reconhecendo as limitações dessa hipótese (Freud, 1915/1982a), o autor relacionará mais tarde o prazer e o desprazer à diminuição ou aumento da excitação não-ligada (Freud, 1920/1955, pp. 7-8). Também são de natureza essencialmente quantitativa os conceitos de pulsão (Gomes, 2001), angústia, afeto, libido, etc.

A concepção quantitativa foi um elemento indispensável desde o início da teorização freudiana. Em 1894, explicita assim sua hipótese de trabalho:

nas funções anímicas algo deve ser distinguido-uma quota de afeto ou soma de excitação-que possui todas as características de uma quantidade (embora não tenhamos meio de medi-la), que é capaz de aumento, diminuição, deslocamento e descarga, e que está espalhada sobre os traços de lembrança das representações até certo ponto como uma carga elétrica está espalhada sobre a superfície de um corpo. (Freud, 1894/1962, p. 60)

Nos Estudos sobre a histeria, está em questão um excesso de estimulação, do qual uma parte pode ser submetida à conversão, enquanto outra parte fica na esfera psíquica sob a forma de sintomas psíquicos (Freud, 1895/1955b).

$\mathrm{O}$ aspecto quantitativo da teoria freudiana foi também importante para uma de suas concepções fundamentais, a da continuidade entre o normal e o patológico - a diferença entre os dois dependendo unicamente de uma relação quantitativa."Depende de relações quantitativas, das relações entre as forças em luta umas contra as outras, que o combate leve ou não à saúde, à neurose ou a desempenhos superiores por compensação" (Freud, 1910/1993, p. 50). Uma relação quantitativa está também está na base de sua teoria do recalcamento. A condição para esse é que a força do desprazer que seria despertado pela satisfação de uma pulsão seja maior que a do prazer que seria obtido (Freud, 1915c, p. 108).

Bergson mantém que, se bem que admitamos ordinariamente que "os estados de consciência (...) são passíveis de crescer e de diminuir", a aplicação da "distinção do mais e do menos" à "região dos fatos subjetivos e das coisas sem extensão" constitui "um problema muito mais grave do que geralmente se imagina" (Bergson, 1927/1961, p. 1). Com efeito, como pode-se "ainda falar de grandeza onde não há nem multiplicidade nem espaço!" (Bergson, 1927/1961, p. 7). Para Freud, ao contrário, como a base dos fenômenos psíquicos é concebida como fisiológica, a formulação quantitativa é não somente possível como necessária. Mais que 
isso, ela não se aplica unicamente ao substrato dos fenômenos conscientes, mas também a outros processos inferidos a partir desses.

\section{O ponto de vista tópico}

Outra consequiência do ponto de vista freudiano sobre a relação mente cérebro, um pouco mais específica, diz respeito à estrutura espacial de seu "aparelho psíquico". O próprio conceito de aparelho (Apparat) é evidentemente de inspiração naturalista. Esse aparelho é concebido como tendo uma extensão espacial. Para Descartes, os fenômenos psíquicos são uma res cogitans, cuja primeira característica é a ausência de extensão espacial. Descartes se ocupou das relações entre a mente e o cérebro, mas para ele essas relações são fundamentalmente de exterioridade, não representando o cérebro mais que o papel de um intermediário entre o resto do corpo e a mente. Para o neurologista Freud, os fenômenos psíquicos são a atividade de sistemas neurais, tendo o cérebro não somente, como todo corpo físico, uma extensão no espaço, mas também uma diferenciação estrutural já conhecida pela anatomia de seu tempo.

Mesmo se, mais tarde, ele renuncia a abordar as relações entre o aparelho psíquico e a anatomia, a dimensão tópica do aparelho psíquico é a herdeira de suas primeiras idéias e a consequiência da persistência de sua concepção de base sobre a natureza do psíquico. Seria, na verdade, difícil imaginar a formulação da teoria de um aparelho psíquico espacialmente estruturado por alguém que adotasse a tese do psíquico como essencialmente imaterial e desprovido de extensão no espaço.

\section{A concepção freudiana da relação mente-cérebro}

Como poderíamos definir, mais precisamente, a concepção freudiana da relação mente-cérebro? Trata-se de uma posição paralelista ou de uma teoria da identidade psiconeural $?^{4}$

A título comparativo, vejamos como Hughlings Jackson coloca o problema e sua posição sobre o mesmo:

Não sou competente para discutir a questão metafísica da natureza da relação da mente com as atividades nervosas. Há três doutrinas: 1) que a mente age sobre o sistema nervoso (...) supõese que uma instância imaterial produza efeitos físicos; 2) que as atividades dos centros superiores e os estados mentais são uma única e mesma coisa, ou aspectos diferentes de uma coisa. Uma terceira doutrina; 3) a que eu adotei, diz que a) os estados de consciência (ou, sinonimamente, os estados da mente) são total-

4 É surpreendente que um grande conhecedor da obra de Freud como James Strachey tenha podido se enganar sobre sua concepção da relação mente-cérebro, como prova a seguinte afirmação, onde faz referência ao Projeto de uma psicologia: "A necessidade de postular quaisquer processos mentais inconscientes foi, dessa forma, completamente evitada: a cadeia de eventos físicos era ininterrupta e completa" (Strachey, 1957, p. 163, ênfase acrescentada). Ora, é claro que, no Projeto, Freud trata de processos mentais inconscientes, embora supondo para eles mecanismos físicos (neurais). E, como vimos acima, sua posição geral sobre a relação mente-cérebro não mudou, ao longo de sua obra. Não há, para ele, incompatibilidade entre o mental e o físico. mente diferentes dos estados nervosos dos centros superiores; $b$ ) as duas coisas ocorrem juntas, e para cada estado mental há um estado nervoso correlativo; c) mesmo se as duas coisas ocorrem em paralelo, não há interferência de uma sobre a outra. (...) Um crítico (...) diz que a doutrina da concomitância é a "teoria dos dois relógios” de Leibniz (...) (Jackson, 1877, p. 84).

O leitor se lembrará que a "teoria dos dois relógios" é uma teoria dualista, segundo a qual a mente e os processos neurais são duas realidades nitidamente diferentes, mas uma funciona em correspondência com a outra, mesmo sem haver relações causais entre elas - como dois relógios que funcionam em sincronia mesmo se não é um que causa o movimento do outro.

Em seu livro sobre as afasias, Freud parece adotar esta posição paralelista de Jackson: “O processo psíquico é, assim, paralelo ao processo fisiológico (a dependent concomitant)"

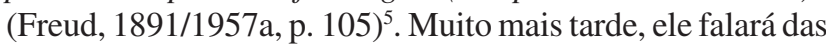
"dificuldades insolúveis do paralelismo psicofísico" (Freud, 1915/1982c, pp. 126-127).

No Projeto, sua posição parece poder ser classificada como uma teoria do duplo aspecto, restrita a uma parte dos processos psíquicos:

Segundo uma teoria mecanicista avançada, a consciência é um simples acessório dos processos fisiológico-psíquicos, cuja não ocorrência nada alteraria ao transcorrer psíquico. Segundo outra doutrina, consciência é o lado subjetivo de todo acontecer psíquico e é, portanto, inseparável do processo anímico fisiológico. Entre as duas se situa a teoria desenvolvida aqui. A consciência é aqui o lado subjetivo de uma parte dos processos físicos do sistema nervoso, a saber, os processos $\omega$, e a não-ocorrência da consciência não deixa o acontecer psíquico inalterado, mas inclui em si a não ocorrência da contribuição de $\omega . ”$ (Freud, 1950/1987, pp. 403-404)

O "lado subjetivo" é um dos aspectos, dentro da teoria dos dois aspectos (um objetivo, outro subjetivo) sobre a relação mente-cérebro. Se a ausência da consciência implica na ausência de uma certa parte dos processos anímicos fisiológicos, é que esses processos e a consciência correspondem a dois aspectos de uma única e mesma coisa (Gomes, 2003). Essa citação, assim como as da primeira parte deste trabalho, permite aproximar a posição de Freud de uma teoria da identidade psiconeural. Entretanto, ele sempre considerou a consciência como um fenômeno singular ou, como dirá em 1938, "um fato incomparável e que se opõe a toda explicação e descrição" (Freud, 1938/1941, p. 79).

É interessante que, como observa Barros (1971), o dualismo paralelista de Jackson suscita um "monismo materialista" no plano metodológico:

O leitor não deve esquecer que uma distinção absoluta é feita (...) entre os estados mentais e seus estados físicos correspondentes, e que nenhuma tentativa é feita de explicar os primeiros pelos últimos (...) não nos ocupamos diretamente da psicologia,

5 A expressão "a dependent concomitant" está em inglês no original e Strachey a atribui a Jackson. 
mas de certas questões da anatomia e da fisiologia do sistema nervoso. (Jackson, 1877, p. 41)

Freud, ao contrário, em seu Projeto, se ocupará da psicologia e tentará explicar os estados psíquicos com hipóteses fisiológicas. Numa de suas últimas obras, o Esboço da psicanálise, de 1938, o autor retoma a questão da relação mente-cérebro. Iniciando essa discussão, qualifica a consciência como um fato incomparável, que resiste a qualquer explicação ou descrição. Como vimos na citação reproduzida na seção intitulada "O problema mente-cérebro em Freud, após 1900", comenta que para muitos basta supor que só a consciência seja o psíquico, caso em que sobraria para a psicologia apenas uma classificação dos estados conscientes. Observa que os processos conscientes não formam sequiências ininterruptas e completas, de modo que não há alternativa senão supor que há processos físicos ou somáticos concomitantes ao psíquico (consciente), aos quais se deve atribuir uma completude maior, já que alguns deles não têm processos paralelos conscientes. É nesses processos somáticos, propõe, que se deve ver o psíquico propriamente dito. E completa: "[A psicanálise] explica os alegados processos concomitantes somáticos como o verdadeiro psíquico ["das eigentlich Psychische"] e com isso desconsidera a princípio a qualidade da consciência" (Freud, 1938/1941, p. 80).

Com base nessa discussão, podemos ver a posição freudiana como uma teoria da identidade psiconeural: o psíquico é o próprio neural. Se considerarmos que o problema mentecérebro é fundamentalmente o problema mente conscientecérebro (Gomes, 1995), podemos ver também sua posição como uma teoria dos dois aspectos: a consciência é algo inexplicável, mas corresponde a uma parte dos processos cerebrais psíquicos. Aquilo que se mostra à consciência seria, então, um outro aspecto desses processos cerebrais (Gomes, 2003).

\section{Conclusão}

Verificamos que, ao longo de toda sua obra, Freud mantém uma posição monista materialista a respeito da relação mente-cérebro. Apesar de ter abandonado a pretensão de oferecer hipóteses específicas sobre os mecanismos fisiológicos dos processos psíquicos, passando a não considerá-las como realmente necessárias, o autor nunca abandonou a concepção de que os processos psíquicos têm um substrato neurofisiológico. Essa concepção de base se manifesta em três aspectos fundamentais da teoria psicanalítica. Ela tornou possível ao autor desenvolver uma teoria dos processos psíquicos causalista, manifestada na forte aderência do autor ao determinismo psíquico, só abrandada em sua construção teórica pela noção de sobredeterminação, que impõe um limite prático à tentação de buscar uma elucidação completa desse determinismo. Em segundo lugar, possibilitou basear sua teoria em concepções quantitativas, ainda que metodologicamente não houvesse recurso a qualquer forma de mensuração. Em terceiro lugar, a teoria atribui ao aparelho psíquico uma dimensão espacial, na forma da postulação de uma tópica psíquica. Essa concepção, que um autor dualista dificilmente abraçaria, deriva naturalmente da visão dos processos psíquicos como derivados da atividade neural.

\section{Referências}

Atlan, H. (1992). Entre o cristal e a fumaça: Ensaio sobre a organização do ser vivo. (V. Ribeiro, Trad.) Rio de Janeiro: Jorge Zahar. (Trabalho original publicado em 1979).

Barros, C. P. (1971). Thermodynamic and evolutionary concepts in the formal structure of Freud's metapsychology. Em S. Arieti (Org.), The world biennial of psychiatry and psychotherapy (pp. 72-111). New York: Basic Books.

Bergson, H. (1961). Essai sur les données immédiates de la conscience. Paris: P.U.F. (Originalmente publicado em 1927).

Binswanger, L. (1970). Discours, parcours et Freud. Paris: Gallimard.

Erikson, E. H. (1955). Freud's "The Origins of Psychoanalysis." International Journal of Psycho-Analysis, 36, 1-15.

Freud, S. (1941). Abriss der Psychoanalyse. Em Gesammelte Werke, Vol. 17. Frankfurt am Main: Fischer. (Originalmente publicado em 1938).

Freud, S. (1946). Zur Einführung des Narzissmus. Em Gesammelte Werke, Vol. 10. Frankfurt am Main: Fischer. (Originalmente publicado em 1914).

Freud, S. (1953a). Three essays on the Theory of Sexuality. Em Standard Edition, Vol. 7. Londres: The Hogarth Press. (Originalmente publicado em 1905).

Freud, S. (1953b). The interpretation of dreams. Em Standard Edition, Vol. 5. Londres: The Hogarth Press. (Originalmente publicado em 1900).

Freud, S. (1955). Studies on hysteria. Em Standard Edition, Vol. 2. Londres: The Hogarth Press. (Originalmente publicado em 1895).

Freud, S. (1955a). Beyond the pleasure principle. Em Standard Edition, Vol. 18. Londres: The Hogarth Press. (Originalmente publicado em 1920).

Freud, S. (1957a). Appendix B. Em Standard Edition, Vol. 14. Londres: The Hogarth Press. (Originalmente publicado em 1891).

Freud, S. (1957b). Mourning and melancholia. Standard Edition, Vol. 14. Londres: The Hogarth Press. (Originalmente publicado em 1917).

Freud, S. (1960). The psychopathology of everyday life. Em Standard Edition, Vol. 6. Londres: The Hogarth Press. (Originalmente publicado em 1901).

Freud, S. (1960). Jokes and their Relation to the Unconscious. Em Standard Edition, Vol. 8. Londres: The Hogarth Press. (Originalmente publicado em 1905).

Freud, S. (1962). The neuro-psychoses of defence. Em Standard Edition, Vol. 3. Londres: The Hogarth Press. (Originalmente publicado em 1894).

Freud, S. (1964). Some elementary lessons in psychoanalysis. Standard Edition, Vol. 23. Londres: The Hogarth Press. (Originalmente publicado em 1938).

Freud, S. (1966). Preface to the translation of Bernheim's 'suggestion'. Standard edition, Vol. 1. Londres: The Hogarth Press. (Originalmente publicado em 1888).

Freud, S. (1982a). Die Traumdeutung. Em Studienausgabe, Vol. 2. Frankfurt am Main: Fischer. (Originalmente publicado em 1900).

Freud, S. (1982b). Triebe und Triebschicksale. Em Studienausgabe, Vol. III. Frankfurt am Main: Fischer. ( Originalmente publicado em 1915). 
Freud, S. (1982c). Das Unbewusste. Em Studienausgabe, Vol. III. Frankfurt am Main: Fischer. (Originalmente publicado em 1915).

Freud, S. (1987). Entwurf einer psychologie. Gesammelte werke, nachtragsband. Frankfurt am Main: Fischer. (Originalmente publicado em 1950).

Freud, S. (1993). De la psychanalyse. Em Oeuvres complètes: Psychanalyse, Vol. 10. Paris: Presses Universitaires de France. (Originalmente publicado em 1910).

Freud, S. (1994). Le malaise dans la culture. Em Oeuvres complètes: Psychanalyse, Vol. 18. Paris: Presses Universitaires de France. (Originalmente publicado em 1930).

Gabbi Jr., O. F. (2003). Notas a Projeto de uma Psicologia. Rio de Janeiro: Imago.

Glansdorff, P. \& Prigogine, I. (1971). Structure, stabilité et fluctuations. Paris: Masson.

Gauchet, M. (1992). L'Inconscient cérébral. Paris: Seuil.

Gomes, G. (1995). Self-awareness and the mind-brain problem. Philosophical Psychology, 8(2), 155-165.

Gomes, G. (2001). Os dois conceitos freudianos de 'Trieb'. Psicologia: Teoria e Pesquisa, 17(3), 239-245.

Gomes, G. (2003). A teoria freudiana da consciência. Psicologia: Teoria e Pesquisa, 19(2), 117-125.
Kanzer, M. (1973). Two prevalent misconceptions about Freud's "Project" (1895). Annual of Psychoanalysis, I. New York: Quadrangle/New York Times Book.

Jackson, J. H. (1877). Remarks on evolution and dissolution of the nervous system. Em Selected Writings of John Hughlings Jackson, Vol. 2, Nova York: Basic Books. (Originalmente publicado em 1958).

Laplanche, J. \& Pontalis, J.-B. (1967/1970) Vocabulário da psicanálise. (P. Tamen, Trad.). Santos: Martins Fontes.

Meltzer, D. (1967). The psychoanalytical process. Perthshire, Scotland: CluniePress.

Pavlov, I. (1961). La psychologie et la psychopathologie expérimentales sur les animaux. Em La psychopathologie et la psychiatrie: Oeuvres choisies (pp. 9-27). Moscou: Langues Étrangères.

Ricoeur, P. (1965). De l'interprétation. Paris: Seuil.

Strachey, J. (1957). Editor's note. Em S. Freud, Standard Edition, Vol. 14, (pp. 161-165). Londres: The Hogarth Press.

Recebido em 16.12.2004

Primeira decisão editorial em 22.06.2005

Versão final em 25.07.2005

Aceito em 04.08.2005 